\title{
Geographical Variation of Growth Rhythm, Height, and Hardiness, and Their Relations in Hippophae rhamnoides
}

\author{
Yingmou Yao ${ }^{1}$ and Peter M.A. Tigerstedt \\ Department of Plant Biology, P. O. Box 27, SF-00014 University of Helsinki, Finland \\ Additional index words. phenology, clinal, genetic variation, regression
}

\begin{abstract}
Genetic variation in growth rhythm, hardiness and height of 24 populations from 3 subspecies in sea buckthorn (Hippophae rhamnoides) were studied in a field test. The relative variance component of subspecies varied from $26.2 \%$ to $73.7 \%$ of total variance. Subspecies turkestanica had a growth mode of late start-late finish, ssp. rhamnoides, intermediate start-early finish and ssp. sinensis, early start-intermediate finish. Subspecies rhamnoides had a growth period of 129 days, $\approx 30$ days shorter than the two Asian subspecies. The average height of ssp. rhamnoides was $43.7 \mathrm{~cm}$, about one-third of that for ssp. tarkestanica and sinensis. Subspecies rhamizoides was more hardy than ssp. sinensis, which was still more hardy than ssp. turkestanica. The variance among populations was generally comparable with within population variance. Except for hardiness, variations for all characters were much larger in ssp. rhamnoides than in ssp. sinensis. The total genetic variance (subspecies plus population) varied from $50 \%$ to $84 \%$ of total variance for all characters, except $37 \%$ for secondbracts. Later growth cessation was correlated with longer growth period, taller plants, more severe frost and winter damage. Strong clinal variation showed that the higher the latitude, the earlier the growth cessation, the shorter the growth period and plant height, the more hardy the population. -The results indicated that population selection should bean efficient way for growth rhythm and plant height. Clinal variation provides guidelines for seed and plant transfer as well as plant introduction. With limited collection and management capacity in germplasm conservation, the recommendation is to collect fewer individuals in each population but more populations along latitude.
\end{abstract}

Sea buckthorn is a dioecious shrub or a small tree. It produces edible berries and can fix nitrogen by its root nodules. During the last decade, the plant has received attention for its agricultural, nutritional, medical and ornamental values (Tian, 1985; Eliseev, 1989; Wahlberg and Jeppsson, 1990; Yao and Tigerstedt, 1994). Breeding and cultivation programs are now being carried out in many countries in Asia, Europe and North America.

Genetic variation is the basis for plant adaptation, evolution and breeding. Sea buckthorn is widely distributed on the Eurasian continent. Large morphological variation in height, branching habit, leaves and fruit have been found in natural and cultivated populations (Rousi, 1971; Yao and Zhu, 1985; Zhu and Yao, 1987; Zhang, 1988; Lian and Zheng, 1989; Eliseev, 1989; Zhao et al., 1991; Huang and Tong, 1992). Wide variations in vitamin C and nutrient concentrations have also been reported in a number of studies (Rousi and Aulin, 1977; Plekhanova, 1988; Wahlberg and Jeppsson, 1990; Zhao et al., 1991; Yao et al., 1992). Isozyme studies have shown that there is a large variation within populations and between subspecies (Yao and Tigerstedt, 1993).

Phenology, particularly growth rhythm (including growth initiation, growth cessation and growth period), are often direct indicators of plant adaptation to local conditions. Phonological variation in $H$. rhamnoides has been found in natural populations and field plantations, but genetic variation is confounded with environmental errors or genotype $\times$ environment interactions. Rousi $(1965,1971)$ has observed a topocline for leaf fall and berry ripening in his cytological and taxonomical studies. In two separate population trials of sea buckthom, Zhao ( 1988) (including ssp. sinensis and turkestanica) and Jiang et al. (1989) (only ssp. sinensis) found significant differences in plant height but not phenology among populations of 1-year-old-seedlings during the

Received for publication 8 Mar. 1994. Accepted for publication 12 Sept. 1994. The cost of publishing this paper was defrayed in part by the payment of page charges. Under postal regulations, this paper therefore must be hereby marked advertisement solely to indicate this fact.

'Current address: Dept. of Crop Science and Plant Ecology, Univ. of Saskatchewan, Saskatoon, Saskatchewan, Canada S7N 0W0. sowing year. Later, Zhao et al. (1991) found clinal variation of fruit ripening in ssp. sinensis of the same trial.

In our experiment, variation in growth rhythm and plant height were observed in the sowing year in the nursery (Yao and Tigerstedt, 1994) and also visualized in the field during the last few years. Thus, the purpose of this study is to investigate the extent of the genetic variation in growth rhythm, height growth and hardiness and their correlations in $H$. rhamnoides. This information is hopefully of significance not only for cultivation and breeding programs but also for germplasm collection and conservation in $H$. rhamnoides.

\section{Materials and Methods}

The material used in this study comprised 24 populations from three subspecies of $H$. rhamnoides in a field trial in Helsinki (Table 1). Subspecies rhamnoides was represented by 10 populations, which were collected from Finnish natural populations, except for one from a cultivated population in Helsinki. Subspecies sinensis and turkestanica, both from China, had 12 and 2 populations respectively. Each of those populations was collected from several locations and thus comprised several subpopulations. The Chinese populations used in this study are a subset of that used by Zhao (1988). They are also similar to the populations used by Jiang et al. (1989), although the latter studied ssp. sinensis only.

The trial was established in spring 1991 with 1-year-old seedlings. Bushes from all populations were completely randomized within the test site (20 bushes from each population); 5 bushes from each of the 24 populations were randomly selected and marked for observation.

Twelve components of growth rhythm, plant height and frostwinter hardiness were investigated in the study. Components are treated as characters although they better represent a stage in development on a scale measurement. The names and criteria and definitions for observing those characters at growth initiation and cessation and for scoring frost and winter damage are given in Table 2. In Spring 1992, at growth initiation, budbreak, first bracts 
Table 1. Geographical distribution of Hippophae rhamnoides sample populations.

\begin{tabular}{|c|c|c|c|c|c|}
\hline Subspecies & No. & Population & Country & Lat & Long \\
\hline \multirow[t]{10}{*}{ rhamnoides } & 2 & Ajos & Finland & $65^{\circ} 40^{\prime}$ & $24^{\circ} 36^{\prime}$ \\
\hline & 4 & Virpivieni & Finland & $65^{\circ} 09$ & $25^{\circ} 14^{\prime}$ \\
\hline & 5 & Hailuoto & Finland & $64^{\circ} 56^{\prime}$ & $24^{\circ} 46^{\prime}$ \\
\hline & 8 & Himanka & Finland & $64^{\circ} 07^{\prime}$ & $23^{\circ} 30^{\prime}$ \\
\hline & 9 & Björköby & Finland & $63^{\circ} 22^{\prime}$ & $21^{\circ} 18^{\prime}$ \\
\hline & 11 & Pori & Finland & $61^{\circ} 31^{\prime}$ & $21^{\circ} 29^{\prime}$ \\
\hline & 12 & Rauma & Finland & $61^{\circ} 10^{\prime}$ & $21^{\circ} 26^{\prime}$ \\
\hline & 14 & Merikarvia & Finland & $61^{\circ} 51^{\prime}$ & $21^{\circ} 22^{\prime}$ \\
\hline & 16 & Åland & Finland & $60^{\circ} 13^{\prime}$ & $20^{\circ} 00^{\prime}$ \\
\hline & 17 & Helsinki & Finland & $60^{\circ} 10^{\prime}$ & $24^{\circ} 58^{\prime}$ \\
\hline \multirow[t]{2}{*}{ turkestanica } & 1 & Chabuchar & China & $43^{\circ} 52^{\prime}$ & $81^{\circ} 05^{\prime}$ \\
\hline & 2 & Kongliu & China & $43^{\circ} 25^{\prime}$ & $82^{\circ} 02^{\prime}$ \\
\hline \multirow[t]{12}{*}{ sinensis } & 3 & Hualong & China & $36^{\circ} 03^{\prime}$ & $102^{\circ} 12$ \\
\hline & 4 & Datong & China & $37^{\circ} 10^{\prime}$ & $100^{\circ} 50^{\prime}$ \\
\hline & 5 & Wushan & China & $34^{\circ} 45^{\prime}$ & $104^{\circ} 56$ \\
\hline & 6 & Taian & China & $35^{\circ} 01^{\prime}$ & $106^{\circ} 13$ \\
\hline & 7 & Tianshu & China & $34^{\circ} 20^{\prime}$ & $105^{\circ} 48$ \\
\hline & 8 & Kelan & China & $39^{\circ} 02^{\prime}$ & $111^{\circ} 30^{\prime}$ \\
\hline & 9 & Linfen & China & $37^{\circ} 00^{\prime}$ & $111^{\circ} 40^{\prime}$ \\
\hline & $\cdot 10$ & Youyu & China & $41^{\circ} 10^{\prime}$ & $112^{\circ} 35^{\prime}$ \\
\hline & 11 & Yuxian & China & $39^{\circ} 55^{\prime}$ & $114^{\circ} 30^{\prime}$ \\
\hline & 12 & Liangcheng & China & $40^{\prime} 20^{\prime}$ & $112^{\circ} 15^{\prime}$ \\
\hline & 13 & Liangcheng & China & $40^{\prime} 20^{\prime}$ & $112^{\circ} 15^{\prime}$ \\
\hline & 14 & Liangcheng & China & $40^{\prime} 20^{\prime}$ & $112^{\circ} 15^{\prime}$ \\
\hline
\end{tabular}

and second bracts were observed at 3-day intervals. In fall, at growth cessation, shoot ending, leaf color 1, leaf color 2 and defoliation were observed at an interval of $\approx 1$ week. At growth initiation and cessation, each character was assigned a value; the number of days from 1 May to the date the character appeared. Therefore, the larger the value the later the character appeared. A character was defined as appearing when it first reached the set criterion (Table 2). Growth period was calculated as the difference between leaf color 1 and first bracts: two characters relatively easy to define and with small observation errors. For hardiness, the fist frost damage was observed on 13 Oct. (first damage) and the second on 22 Oct. (second damage) in the same year, while winter damage was observed in Spring 1993. Higher scores represent heavier damage or less hardiness. Plant height was measured at the end of October 1992.

On 22 Oct., when observations ended, almost all Finnish bushes had reached the defoliation stage, while most Chinese bushes were still at the shoot ending or leaf color 1 stage and some had not even stopped shoot elongation. The plants that had not reached defoliation at this time could not progress into this final stage properly because of severe low-temperature damage. As a consequence, these plants had missing values for some characters at growth cessation. If a character was missing at growth cessation, the number of days for this character was derived as the number of days for the previous character plus 6 , which was the approximate number of days needed for one stage to progress into the next for the southernmost Finnish population. Most Chinese bushes were assigned their values for leaf color 2 and defoliation in this way.

In the last few years, winters in the Helsinki area have been rather mild. During the observation year ( 1992-93), the lowest temperature was only $-17.7 \mathrm{C}$ (measured at the nearest weather station, $4 \mathrm{Km}$ from the field). However, during the most recent winter (1993-94), the temperature went down to $-30 \mathrm{C}$ in the experimental
Table 2. Definitions and criteria for observing characters of growth rhythm and hardiness.

\begin{tabular}{|c|c|c|c|c|}
\hline \multicolumn{2}{|c|}{ Character } & Abbreviation & \multicolumn{2}{|r|}{ Criterion } \\
\hline \multicolumn{5}{|c|}{ Growth initiation } \\
\hline \multicolumn{2}{|c|}{ Budbreak } & $\mathrm{Bb}$ & \multicolumn{2}{|c|}{ One-third of buds out of scales } \\
\hline \multicolumn{2}{|c|}{ First bracts } & $\mathrm{Fb}$ & \multicolumn{2}{|c|}{$\begin{array}{l}\text { One-third of first pairs of brac } \\
\text { teal leaves open. }\end{array}$} \\
\hline \multicolumn{2}{|c|}{ Second bracts } & $\mathrm{Sb}$ & \multicolumn{2}{|c|}{$\begin{array}{l}\text { One-third of second pairs of brac } \\
\text { teal leaves open. }\end{array}$} \\
\hline \multicolumn{5}{|c|}{ Growth cessation } \\
\hline \multicolumn{2}{|c|}{ Shoot ending } & $\mathrm{Se}$ & \multicolumn{2}{|c|}{$\begin{array}{l}\text { Three-fourths shoots stopping } \\
\text { elongation }\end{array}$} \\
\hline \multicolumn{2}{|c|}{ Leaf color 1} & Lc1 & \multicolumn{2}{|c|}{$\begin{array}{l}\text { One-third of leaves } \\
\text { turning yellow or falling off. }\end{array}$} \\
\hline \multicolumn{2}{|c|}{ Leaf color 2} & $\mathrm{Lc} 2$ & \multicolumn{2}{|c|}{$\begin{array}{l}\text { Two-thirds of leaves turning yel } \\
\text { low or falling off. }\end{array}$} \\
\hline \multicolumn{2}{|c|}{ Defoliation } & Df & \multicolumn{2}{|c|}{$\begin{array}{l}\text { Complete or almost complete } \\
\text { defoliate. }\end{array}$} \\
\hline \multicolumn{2}{|c|}{ Growth period } & $\mathrm{Gp}$ & \multicolumn{2}{|c|}{ Number of days from $\mathrm{Fb}$ to $\mathrm{Lcl}$} \\
\hline \multicolumn{3}{|c|}{ Frost damage } & \multicolumn{2}{|r|}{ Winter damage } \\
\hline Score & \multicolumn{2}{|c|}{ Criterion } & Score & Criterion \\
\hline$\overline{0}$ & \multicolumn{2}{|c|}{ No obvious leaf damage } & 0 & No obvious branch damage \\
\hline 1 & \multicolumn{2}{|c|}{ Obvious leaf damage } & 1 & Obvious branch damage \\
\hline 2 & \multicolumn{2}{|c|}{ Severe leaf damage } & 2 & $\begin{array}{l}\text { Only main stem and big } \\
\text { branch alive }\end{array}$ \\
\hline 3 & \multicolumn{2}{|c|}{ Young shoot damage } & 3 & $\begin{array}{l}\text { Only the part under snow } \\
\text { alive }\end{array}$ \\
\hline 4 & \multicolumn{2}{|c|}{ Severe young shoot damage } & 4 & Death \\
\hline
\end{tabular}

field on at least two occasions (by our own observations). It appears that the damage was no more severe than the previous winter.

SAS programs CORR, GLM, VCOMP and REG (SAS Institute, 1993) were used for data analysis. Since within-population variance is not separated from experimental error, the error variance also contains a family component in this study.

\section{Results and Discussion}

Genetic variability of growth rhythm, height, and hardiness

Variation at subspecies level. The study found large genetic variations among subspecies for all 12 characters observed (Table 3). Analysis of variance showed that all characters had highly significant variation among subspecies (Table 4). At growth initiation, ssp. turkestanica was 3.9 and 5.4 days later for budbreak, 5.4 and 7.7 days later for first bracts, and 4.2 and 4.7 days later for second bracts than ssp. rhamnoides and sinensis, respectively (Table 3). The variance among subspecies accounted for $45.2 \%, 45.5 \%$, and $26.2 \%$ of total variance for budbreak and first and second bracts, respectively (Table 4).

As at growth initiation, ssp. turkestanica was also later than the other two subspecies at growth cessation. However, the differences were much larger. For shoot ending, ssp. turkestanica was 36.7 and 11.1 days later than ssp. rhamnoides and sinensis, while ssp. sinensis was 25.6 later than ssp. rhamnoides (Table 3). At growth cessation, the relative variance component of subspecies reached $47 \%$ to $70.5 \%$ of the total variance (Table 4 ).

As a consequence, ssp. rhamnoides had a growth period of 128.9 days, $\approx 30$ days shorter than ssp. turkestanica (158.8 days) and sinensis (157.4 days), while no difference was found between the two Asian subspecies because a late start had been offset by a late finish in ssp. turkestanica. The relative variance component of 


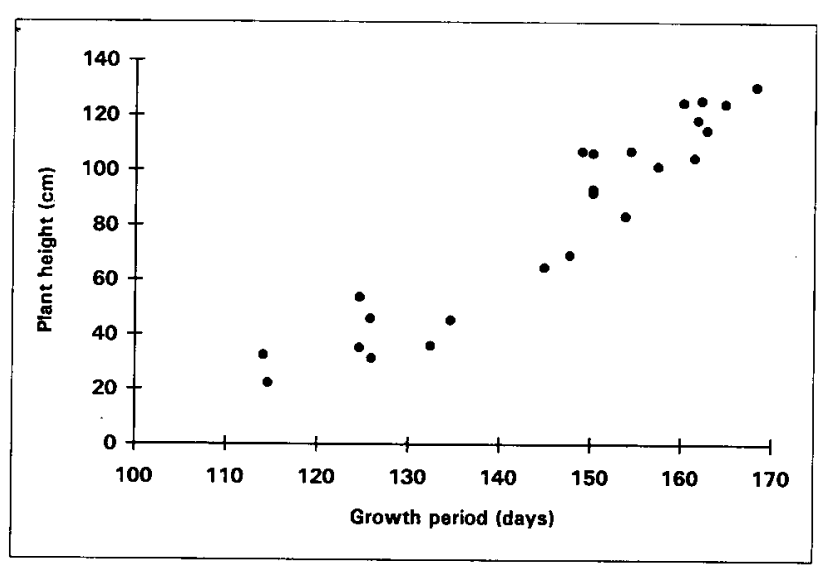

Fig. 1. Relations between plant height and growth period in Hippophae rhamnoides.

be expected from selection for these characters. Variation between populations larger than that within populations has also been found in Pinus massoniana (Chen et al., 1982), Picea sitchensis (Deleporte,

1984), Picea abies (Ununger et al., 1988), Pseudotsuga menziesii (Loopstra and Adams, 1989) and other species.

\section{Correlation between characters}

Since ssp. turkestanica responded quite differently from the other two subspecies and had only two populations, it has been omitted from the correlation analysis. The results of correlation analysis showed that correlations between most characters were highly significant (Table 5).

At growth initiation, budbreak, first bracts and second bracts were closely correlated with each other. The Pearson correlation coefficient $(R)$ varied From 0.78 to 0.87 and all were significant at $P=0.0001$. Correlations of budbreak and first bracts with the other characters were all negative and relatively weak $(R=-0.232$ to 0.442 ) but statistically significant. Second bracts was also negatively correlated with all other characters. However, the correlations were only -0.089 to -0.258 and not significant inmost cases. The uniform negative correlation between growth initiation and other characters suggested an overall trend: the later the growth initiation, the earlier the growth cessation, the shorter the growth period and plant height, and the more hardy the plant (the lesser the frost and winter damage).

Characters at growth cessation were correlated to each other even more closely ( 0.875 to 0.974$)$ than those at growth initiation. It is interesting to note that the correlations at growth initiation and at growth cessation followed a logical relation; i.e. sequentially close characters are correlated more than those that are sequentially less close. For example, the correlation of shoot ending with leaf color 1 was larger than that with leaf color 2, which was still larger than that with defoliation.

Correlations between the four characters at growth cessation and growth period were 0.873 to 0.986 , much larger than those between the characters at growth initiation and growth period. The correlation between leaf color 1 and growth period was 0.986 , the highest among all pairs of characters. It is obvious that the later the growth cessation the longer the growth period. Shoot ending, leaf color 1, leaf color 2 and defoliation were also significantly correlated with height (0.630 to 0.791$)$. Thus, the later the growth cessation, the taller the plant. Correlations of shoot ending, leaf color 1, leaf color 2 and defoliation with first damage, second damage and winter damage varied from 0.508 to 0.618 . The results showed a clear trend; the later the growth cessation, the heavier the frost and winter damage.

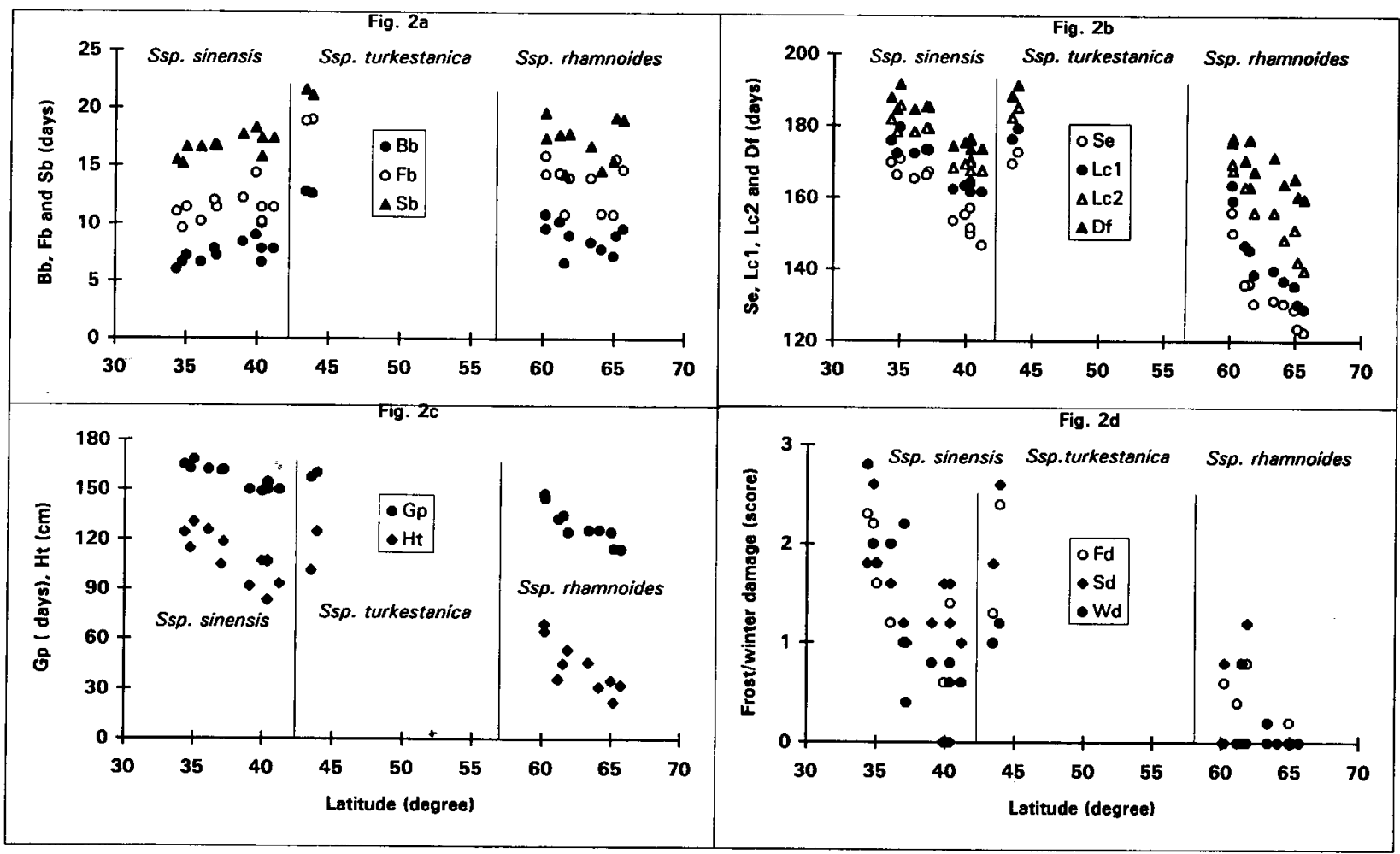

Fig. 2. Response of growth rhythm, height, and hardiness to latitude in Hippophae rhamnoides. See Table 2 for character abbreviations. 
Table 4. Analysis of variance and estimates of variance components for characters ${ }^{2}$ of growth rhythm, height and hardiness in Hippophae rhamnoides.

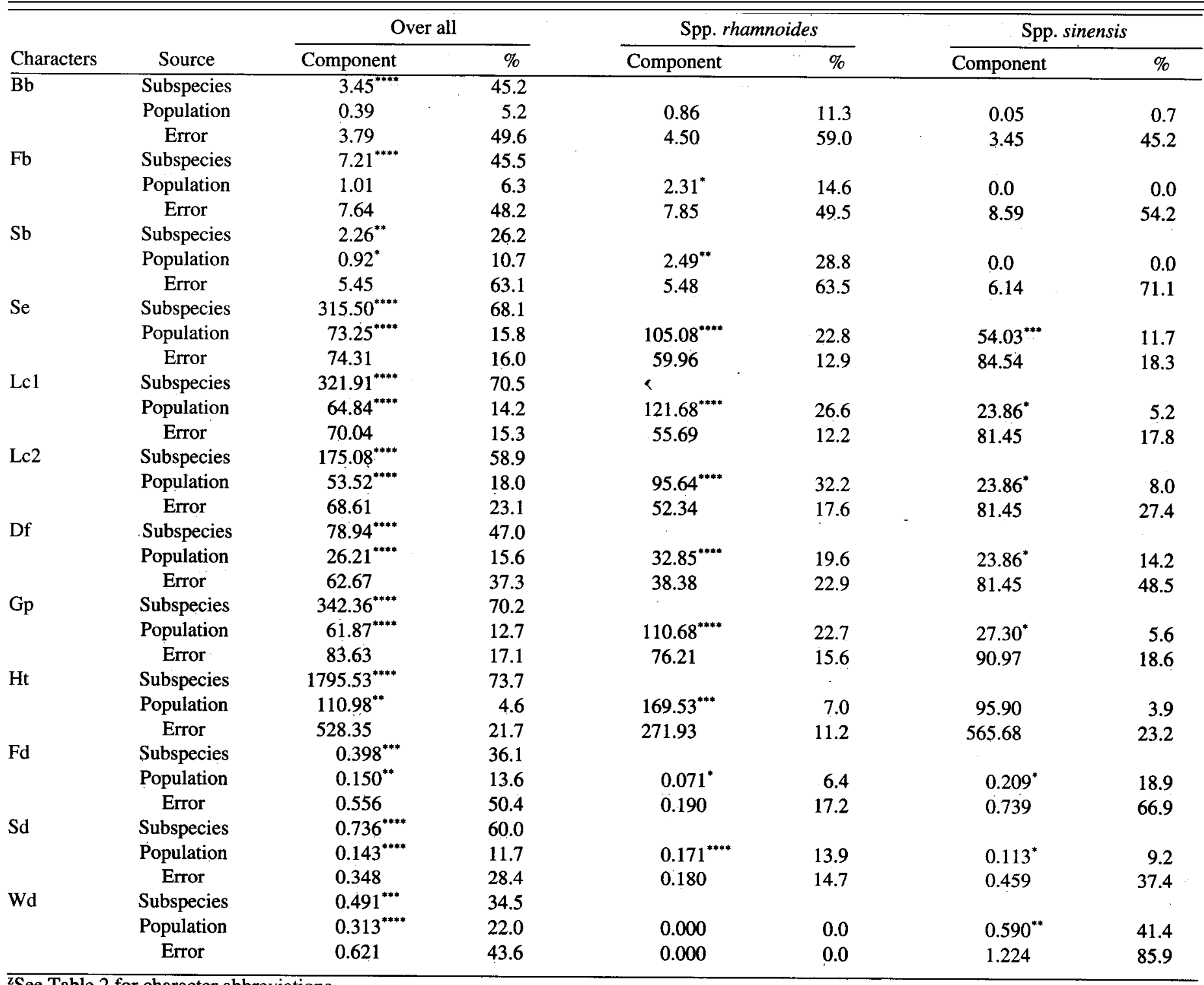

${ }_{\text {zee Table } 2}$ for character abbreviations.

${ }^{* * * * * * * *, * * * *}$ Significant at $P=0.05,0.01,0.001$, or 0.0001 , respectively.

Growth period was closely correlated with height (0.793). Evidently, the longer the growth period, the taller the plant (Fig. 1 ). Growth period and height were moderately correlated with frost and winter damage, with $R$ varying from 0.490 to 0.670 . Plants that had a longer growth period were normally taller and had a greater chance of being frost damaged. Concerning the relation between growth rhythm, plant height and hardiness, similar results have been reported in Picea glauca (Nienstaedt, 1985), Populus nigra and Populus deltoides (Pichot et al., 1988, 1989), and Fagus sylvatica (Cros et al., 1988).

The correlation between first and second frost damage was 0.784. This means that plants suffering from the first frost likely suffered from the second frost as well. The correlation between winter damage and frost damage was rather weak (0.388 to 0.413$)$, suggesting that some plants suffered from frost damage but escaped winter damage.

\section{Clinal variation}

The results showed that most characters in the study were correlated with latitude (Fig. 2). In general, correlations with height, growth period and growth cessation were larger than those with hardiness; which were still larger than those with growth initiation.

Without ssp. turkestanica and on the population mean basis (hereafter), the correlations of latitude with all characters except second bracts were highly significant (at least at 0.01 level). The correlations of latitude with budbreak and first bracts were 0.583 and 0.584 , respectively. The general tendency was that the higher the latitude, the later the growth initiation (Fig. 2a).

All four characters at growth cessation were closely and negatively correlated with latitude $(R=-0.805$ to -0.904$)$, showing definite evidence that the higher the latitude, the earlier the growth cessation (Fig. 2b). Correlations of latitude with growth period and plant height were -0.920 and -0.959 , respectively, the strongest among all characters. The results showed that the higher the latitude, the shorter the growth period and plant height (Fig. 2c). Frost and winter damage were negatively correlated with latitude. Thus the higher the latitude, the less damage or the hardier the population (Fig 2d).

The results of clinal variation with latitude in this study agree 
Table 5. Correlations ${ }^{2}$ among characters of growth rhythm, height and hardiness in Hippophae rhamnoides (see text for abbreviations of characters).

\begin{tabular}{|c|c|c|c|c|c|c|c|c|c|c|c|}
\hline Character & $\mathrm{Bb}$ & $\mathrm{Fb}$ & $\mathrm{Sb}$ & $\mathrm{Se}$ & Lc1 & Lc2 & Df & $\mathrm{Gp}$ & $\mathrm{Ht}$ & $\mathrm{Fd}$ & $\mathrm{Sd}$ \\
\hline \multirow[t]{2}{*}{$\overline{\mathrm{Fb}}$} & 0.8725 & & & & & & & & & & \\
\hline & 0.0001 & & & & & & & & & & \\
\hline $\mathrm{Sb}$ & 0.7795 & 0.8540 & & & & & & & & & \\
\hline \multirow[t]{2}{*}{$\mathrm{Se}$} & -0.2844 & -0.3151 & -0.1564 & & & & & & & & \\
\hline & 0.0027 & 0.0008 & 0.1044 & & & & & & & & \\
\hline Lc1 & -0.2482 & -0.2868 & -0.1176 & 0.9740 & & & & & & & \\
\hline \multirow[t]{2}{*}{ Lc1 } & -0.2687 & -0.2927 & -0.1680 & 0.9380 & 0.9641 & & & & & & \\
\hline & 0.0047 & 0.0020 & 0.0808 & 0.0001 & 0.0001 & & & & & & \\
\hline \multirow[t]{2}{*}{ Df } & -0.2353 & -0.2465 & -0.1541 & 0.8749 & 0.8867 & 0.9228 & & & & & \\
\hline & 0.0138 & 0.0098 & 0.1096 & 0.0001 & 0.0001 & 0.0001 & & & & & \\
\hline \multirow[t]{2}{*}{ Gp } & -0.3838 & -0.4420 & -0.2583 & 0.9667 & 0.9861 & 0.9535 & 0.8731 & & & & \\
\hline & 0.0001 & 0.0001 & 0.0067 & 0.0001 & 0.0001 & 0.0001 & 0.0001 & & & & \\
\hline \multirow[t]{2}{*}{$\mathrm{Sd}$} & -0.3146 & -0.3284 & -0.1866 & 0.6182 & 0.6009 & 0.5899 & 0.5313 & 0.6196 & 0.6697 & 0.7844 & \\
\hline & 0.0009 & 0.0005 & 0.0520 & 0.0001 & 0.0001 & 0.0001 & 0.0001 & 0.0001 & 0.0001 & 0.0001 & \\
\hline \multirow[t]{2}{*}{ Wd } & -0.3673 & -0.3533 & -0.2129 & 0.5568 & 0.5429 & 0.5275 & 0.5300 & 0.5696 & 0.4895 & 0.4089 & 0.3782 \\
\hline & 0.0001 & 0.0002 & 0.0263 & 0.0001 & 0.0001 & 0.0001 & 0.0001 & 0.0001 & 0.0001 & 0.0001 & 0.0001 \\
\hline
\end{tabular}

Correlation coefficient $\mathrm{R} / \mathrm{P} R / P>\mathrm{ORO}$ under $\mathrm{H}_{0}: \mathrm{Rh}_{0}=0$. See Table 2 for character abbreviations.

with the results of Zhao (1988) and Jiang et al. (1989) for plant height, and of Rousi $(1965,1971)$ and Zhao et al. (1991) for growth rhythm in $H$. rhamnoides. Clinal variation in growth rhythm, plant height and hardiness with respect to latitude has been found in apples (Nesterov, 1983), Betula pendula and B. pubesces (Pelham et al., 1984), Populus trichocapa (Weber et al., 1985), Vaccinium myrtillus (Vanninen et al., 1988), Pinus taeda and Liquidambar styractifua (Wells et al., 1991), and many other species.

\section{Regression models}

Because most characters were closely correlated with latitude, regression models for projecting those characters by latitude were built. Although the same characters in ssp. rhamnoides and ssp. sinensis normally had similar response trends to the change of latitude, the strength of response was different (Fig 2). Thus, separate models for each subspecies were constructed on the basis of population means. The ones that were statistically significant are presented in Table 6 . In addition, the regression equations of plant height on growth period, based on population means, are also presented for the two subspecies.

According to the coefficient of determination $\left(R^{2}\right)$ and probability $(\boldsymbol{P})$, all regression equations, except the one for second bracts, had fairly good prediction powers. The best were those for characters at growth cessation and growth period. The results showed that winter damage could be predicted rather precisely in ssp. sinensis. This is of importance for future introduction and breeding plans.

The two groups of equations in Table 6 showed that ssp. rhamnoides always responds more strongly to a change in latitude, i.e. has a steeper slope than ssp. sinensis. In other words, increase or decrease of one degree in latitude will result in a larger change for characters in ssp. rhamnoides than in ssp. sinensis. Increasing latitude 10 will lead to a decrease of plant height by $6 \mathrm{~cm}$ in ssp. rhamnoides but $4.6 \mathrm{~cm}$ in ssp. sinensis. For growth period, an increase of 10 in latitude will cause a decrease of 4.9 days in ssp. rhamnoides and 2.5 days in ssp. sinensis. Reactions were similar for other characters.
Plant heights responded to growth period more strongly in ssp. sinensis than in ssp. rhamnoides. An increase of 1 day in growth period will result in an increase of $1.68 \mathrm{~cm}$ in plant height in ssp. sinensis, $47 \%$ more than that in ssp. rhamnoides $(1.14 \mathrm{~cm})$. In other words, ssp. sinensis uses growth period more efficiently than ssp. rhamnoides for height growth. Thus, the fast-growing bushes or populations are explained not only by longer growth period but also by their efficient use of growth period or fast speed of growth. Similar results has also been found in jack pine (Riemenschneider, 1983; Magnussen and Yeatman, 1989).

\section{Some thoughts for a plant breeding strategy}

In the present study, the observations were made only in one year and one location because of practical limitations. Thus, population $\mathrm{x}$ year (or location) effects could provide bias to populations variance estimates. Genotype $\mathrm{x}$ environment interactions are often an important component in yield characters such as volume, grain and fruit yield. However, most characters observed in this study are phonological to which we do not expect large GxE interactions. Furthermore, our early study in the nursery (Yao and Tigerstedt, 1994) and visual observations in 1991 and 1992 agreed with present results very well, showing large and clinal variation of growth rhythm and height in this material. Therefore, we are confident that the trends shown in this study would not change even if the experiment was conducted for several years and at several locations.

The results showed large genetic variation residing in $H$. rhamnoides at subspecies, population and individual levels. Since the genetic variation among subspecies and population is very large, it would be better for breeders to start their breeding programs at the population level, i.e., population selection first. The selected populations will be the base or breeding populations for further family or individual selection. The selected families or individuals may be released after tests as cultivars or further crossed with each other to produce population hybrids. It maybe desirable to hybridize with unselected populations or subspecies to 
Table 6. Regression models for predicting characters of growth rhythm, height, and hardiness ( $\mathrm{L}=$ latitude, see Table 2 for other abbreviations).

\begin{tabular}{|c|c|c|c|c|c|}
\hline \multicolumn{3}{|c|}{ Ssp. sinensis } & \multicolumn{3}{|c|}{ Ssp. rhamnoides } \\
\hline Equation & $R^{2}$ & $P$ & Equation & $R^{2}$ & $P$ \\
\hline $\mathrm{Ht}=282.1-4.5625 \mathrm{~L}$ & 0.620 & 0.0024 & $\mathrm{Ht}=422.4-6.0296 \mathrm{~L}$ & 0.687 & $\overline{0.0030}$ \\
\hline $\mathrm{Gp}=251.6-2.4823 \mathrm{~L}$ & 0.844 & 0.0001 & $\mathrm{Gp}=434.7-4.8682 \mathrm{~L}$ & 0.818 & 0.0003 \\
\hline $\mathrm{Se}=279.4-3.1456 \mathrm{~L}$ & 0.870 & 0.0001 & $\mathrm{Se}=418.2-4.5159$ & 0.758 & 0.0011 \\
\hline $\mathrm{Lcl}=257.7-2.3454 \mathrm{~L}$ & 0.853 & 0.0001 & $\mathrm{Lcl}=460.1-5.0569 \mathrm{~L}$ & 0.837 & 0.0002 \\
\hline $\mathrm{Lc} 2=263.7-2.3454 \mathrm{~L}$ & 0.853 & 0.0001 & $\mathrm{Lc} 2=453.7-4.7439 \mathrm{~L}$ & 0.922 & 0.0001 \\
\hline $\mathrm{Df}=263.7-2.3454 \mathrm{~L}$ & 0.853 & 0.0001 & $\mathrm{Df}=340.8-2.7453 \mathrm{~L}$ & 0.806 & 0.0001 \\
\hline $\mathrm{Fd}=7.978-0.18014 \mathrm{~L}$ & 0.530 & 0.0072 & & & \\
\hline $\mathrm{Sd}=5.814-0.11412 \mathrm{~L}$ & 0.397 & 0.0280 & & & \\
\hline $\mathrm{Wd}=13.143-0.31557 \mathrm{~L}$ & 0.710 & 0.0006 & & & \\
\hline $\mathrm{Ht}=-115.8+1.6820 \mathrm{Gp}$ & 0.615 & 0.0025 & & & \\
\hline $\mathrm{Ht}=-103.6+1.1422 \mathrm{Gp}$ & 0.714 & 0.0021 & & & \\
\hline
\end{tabular}

gain some special traits at this stage.

Clinal variation of growth rhythm, height and hardiness provides guidelines for seed and plant transfer as well as plant introduction. It also provides good opportunity for plant breeding and selection, particularly for designing breeding programs. Clinal variation of growth rhythm must predominantly be determined by additive genes, thus, hybrids would be intermediate. Breeders can use this information to predict the performance of their hybrids based on the parental populations and to design their breeding plan to obtain an ideal type with certain growth period, maturity time and plant height for a particular cultivation region or cultivation technology. For example, by crossing their breeds with populations of northern origins, breeders may get dwarf or semidwarf hybrids with early maturity. For mechanical harvest, breeders may want to produce hybrids of intermediate height by crossing their breeds with tall populations.

The regression models provide good predictions for growth rhythm, plant height and hardiness. Thus breeders and growers may use them as guidelines for selecting populations in designing breeding and cultivation programs. This will reduce the time, labor and money wasted and promote the genetic gain.

Germplasm conservation should concern all levels of genetic diversity in $H$. rhamnoides. Clinal variation in growth rhythm, plant height and hardiness indicates that germplasm sampling should be among populations along latitude. With limited collection and management capacity, the recommendation is to collect fewer individuals in each population but more populations along latitude.

\section{Literature Cited}

Chen, Y. W., W.M. Chen, D.L. Liu, R.H. Zhen, C. Zhou, Y.Q. Kang, and Zhang JQ. 1982. Genetic variations between populations and individuals of masson pine in Fujian Province. J. Nanjing Tech. College For. Prod. 2:29-43 (in Chinese, summary in English).

Cros, E.T. du, B. Thiebaut, and E. Teissier du Cros. 1988. Variability in beech: budding, height growth and tree form. Annales des Sciences Forestieres 45(4):383-398.

Deleporte, P. 1984. Results and methodology for the selection of Sitka spruce using several characteristics. Annales de Recherches Sylvicoles, AFOCEL 1983, Paris. p. 282-337 (in French, summary in English).

Eliseev, I.P. 1989. Evolutionary genetical aspects in assessment of achievements and perspectives of sea buckthorn selection in the USSR. Proc. Intl. Sea Buckthorn (Hippophae) Symp., Xian, China, p. 184-193.

Huang, Q. and J. Tong. 1992. Research on the variations of major economic traits of Subsp. sinensis Rousi. Hippophae 2: 18-21 (in Chinese).

Jiang, C., R. Zhu, and H. Zhang. 1989. The growth analysis of Hippophae provenance trial at the seedling stage. Hippophae 1:23-26 (in Chinese).
Lian, Y. and H. Zheng. 1989. A research on dividing infraspeceific patterns within Hippophae rhamnoides L. ssp sinensis. Proc. Intl. Sea Buckthorn (Hippophae) Symp., Xian, China, p. 31-34.

Loopstra, C.A. and W.T. Adams. 1989. Patterns of variation in first-year seedlings traits within and among Douglas-fir breeding zones in southwest Oregon. Silvae Genetics 38(5-6):235-243.

Magnussen, S. and C.W. Yeatman: 1989. Height growth components in inter- and intra-provenance jack pine families. Can. J. For. Res. 19(8):962972.

Nesterov, Y.S. 1983. Geographical variation in rhythm of the annual life cycle in apple varieties. Trudy po prikladnoi botanike, genetike i selektsii 79:129-138 (in Russian, summary in English).

Nienstaedt, H. 1985. Inheritance and correlations of frost injury, growth, flowering, and cone characteristics in white spruce, Picea glauca (Moench) Voss. Can. J. For. Res. 15(3):498-504.

Pelharn, J., J.W. Kinnaird, A.S. Gardiner, and F.T. Last. 1984. Variation in, and reproductive capacity of Betula Pendula and B. pubescens. Proc. Royal Soc. Edinburgh Biol. Sci. 85(1/2):27-41.

Pichot, C., E.T. du Cros, and E. Teissier du Cros. 1988. Estimation of genetic parameters in the European black poplar (Populus nigra L.). Consequences on the breeding strategy. Annales des Sciences Forestieres 45(3):223-237.

Pichot, C., E.T. du Cros, and E. Teissier du Cros. 1989. Estimation of genetic parameters in eastern cottonwood (Populus deltoides Bartr.). Consequences for the breeding strategy. Annales des sciences Forestieres 46(4):307-324.

Plekhanova, M.N. 1988. Sea buckthorn. (in Russian).

Riemenschneider D.E. 1983. Height and seasonal growth pattern of jack pine full-sib families. Proc. 2nd. North Central Tree Improvement Conf., Lincoln Neb. p. 147-158.

Rousi, A. 1965. Observations on the cytology and variation of European and Asiatic populations of Hippophae rhamnoides. Ann. Bet. Fenn. 2:1-18.

Rousi, A. 1971. The genus Hippophae: A taxonomic study. Ann. Bet. Finn. 8:177-277.

Rousi, A. and H. Aulin. 1977. Ascorbic acid content in relation to ripeness in fruits of six Hippophae rhamnoides clones from Pyhäranta, SW Filand. Ann. Agr. Fenn. 16:80-87.

SAS Institute. 1993. SAS Procedures guide. version 6. 3rd ed. SAS Institute, Cary, N.C.

SAS Institute. 1993. SAS/STAT user's guide. version 6. 4th ed. vol. 2. SAS Institute, Cary, N.C.

Tian, H. 1985. Hippophae: cultivation and development. Shaanxi Agr. Info. Press. 32 p. (in Chinese).

Ununger, J., L Ekberg, and H. Kang. 1988. Genetic control and age-related changes of juvenile growth characters in Picea abies. Stand. J. For. Res. 3(1):55-66

Vanninen, I., S. Laakso, and M. Raatikainen. 1988. Geographical variation in the phenology and morphology of bilberry in Finland. Acts Bet. Finn. 136:49-59.

Wahlberg, K. and N. Jeppsson. 1990. Development of cultivars and growing techniques for sea buckthorn, black chokeberry. Lonicera and 
Sorbus. Sverigges Lantbruksuniversitedt Balsgåard-Avdelningen for Hortikulturell Växtförädling Verksamhetsberättelse 1988-1989. p. 8093 (in Swedish, summary in English).

Weber, J. C., R.F. Stettler, and P.E. Heilman. 1985. Genetic variation and productivity of Populus trichocarpa and its hybrids. I. Morphology and phenology of 50 native clones. Can. J. For. Res. 15(2):376-383.

Wells, O.O., G.L. Switzer, and R.C. Schmidtling. 1991. Geographic variation in Mississippi loblolly pine and sweetgum. Silvae Genet. 40(34):105-119.

Yao, Y. and C. Zhu. 1985. Investigation on natural resources of sea buckthorn in West-Shanxi Plateau. Shanxi Sci. Technol. For. 4:32-35 (in Chinese).

Yao, Y. and P.M.A. Tigerstedt. 1993. Isozyme studies of genetic diversity and evolution in Hippophae. Genetic Resources and Crop Evolution, 40:153-164.
Yao, Y. and P.M.A. Tigerstedt. 1994 Genetic diversity in Hippophae L. and its use in plant breeding. Euphytica 77:165-169.

Yao, Y., P.M.A. Tigerstedt, and P. Joy. 1992. Variation of vitamin C concentration and character correlation between and within natural sea buckthom (Hippophae rhamnoides L.) populations. Acta Agr. Stand. 42:12-17.

Zhang, G. 1988. A study on the germplasm resources and superior tree of Hippophae. Hippophae 2:10-15 (in Chinese).

Zhao, H. 1988. Provenance trial on Hippophae rhamnoides at its seedling stage. Hippophae 4:11-18 (in Chinese).

Zhao, H., C. Zhu, C. Gao, H. Li, Z. Liu, and W. Sun. 1991. Geographical variations of fruit traits of the Chinese sea buckthorn and selection of provenances for fruit use. Hippophae 4:15-18 (in Chinese).

Zhu, C. and Y. Yao. 1987. Variation of thorns in sea buckthorn. Res. Rpt. Res. Inst. For., Chinese Acad. For. 1 :55-59 (in Chinese). 